\title{
Physical Understanding of Human-Induced Changes in U.S. Hot Droughts Using Equilibrium Climate Simulations ${ }^{\mathscr{Q}}$
}

\author{
LINYIN CHENG \\ Department of Geosciences, University of Arkansas, Fayetteville, Arkansas \\ MARTIN HOERLING \\ Physical Sciences Division, Earth System Research Laboratory, National Oceanic and Atmospheric \\ Administration, Boulder, Colorado \\ ZHIYONG LIU \\ Department/Center of Water Resources and Environment, and Guangdong Engineering Technology Research \\ Center of Water Security Regulation and Control for Southern China, Sun Yat-Sen University, Guangzhou, China \\ JON EISCHEID \\ Cooperative Institute for Research in Environmental Sciences, University of Colorado Boulder, Boulder, Colorado
}

(Manuscript received 17 September 2018, in final form 12 April 2019)

\begin{abstract}
Although the link between droughts and heat waves is widely recognized, how climate change affects this link remains uncertain. Here we assess how, and by how much, human-induced climate change affects summertime hot drought compound events over the contiguous United States. Results are derived by comparing hot drought statistics in long simulations of a coupled climate model (CESM1) subjected to year-1850 and year-2000 radiative forcings. Within each climate state, a strong and nonlinear dependency of heat-wave intensity on drought severity is found in water-limited regions of the southern Great Plains and southwestern United States whereas heat-wave intensity is found to be insensitive to drought severity in energy-limited regions of the northern and/or northeastern United States. Applying a statistical model that is based on paircopula constructions, we find that anthropogenic warming leads to enhanced soil moisture-temperature coupling in water-limited areas of the southern Great Plains and/or southwestern United States and consequently amplifies the intensity of extreme heat waves during severe droughts. This strengthened coupling accounts for a substantial fraction of rising temperature extremes related to the long-term climate change in CESM1, highlighting the importance of changes in land-atmosphere feedback in a warmer climate. In contrast, coupling effects remain weak and largely unchanged in energy-limited regions, thereby yielding no appreciable contribution to heat-wave intensification over the northern and/or northeastern United States apart from the long-term warming effects.
\end{abstract}

\section{Introduction}

Extreme and prolonged heat waves are often bolstered by reinforcing land surface feedbacks related to drought conditions (e.g., NCDC 2012; Stefanon et al.

Supplemental information related to this paper is available at the Journals Online website: https://doi.org/10.1175/JCLI-D-180611.s1.

Corresponding author: Linyin Cheng, 1c032@uark.edu
2012; Hoerling et al. 2013; Dai 2013; Seager and Hoerling 2014). If soil moisture is lacking, latent heat losses from land surface due to evapotranspiration are greatly reduced (Chang and Wallace 1987; Fischer et al. 2007a; Dole et al. 2011). This reduction is mainly balanced by increased upward sensible fluxes, thereby contributing to enhanced warming of air temperatures (Fischer et al. 2007b; Ferranti and Viterbo 2006; Dirmeyer 2006; Livneh and Hoerling 2016). This process is referred to as soil moisture-temperature feedback, a key to the development of mega-heat waves (Beniston 
2004; Hirschi et al. 2011; Miralles et al. 2014) and drought persistence (Durre et al. 2000; Peterson et al. 2013). Although the link between droughts and heat waves is widely recognized (e.g., Cook et al. 2014, 2015; Mo and Lettenmaier 2015), how climate change affects this link remains unclear (Teng et al. 2016).

Previous studies for the summertime European continent (Schär et al. 2004; Vidale et al. 2007) found that a trend toward rising temperature is accompanied by a trend to increased temperature variability, engendered by changes in the land-atmosphere coupling over $\mathrm{Eu}$ rope (Seneviratne et al. 2006). Heat waves have generally become more frequent across portions of the United States in recent decades (Meehl and Tebaldi 2004; Knutson et al. 2018), with western regions setting records for numbers of these events in the 2000s since the start of reliable instrumental records in 1895 (Walsh et al. 2014). The particular interests of this study are twofold: 1) to explore whether there are any significant anthropogenic-forced changes in the coupling between drought and heat waves over the United States, which can make hot droughts hotter and 2) to characterize its regional dependency on how drought-heat-wave coupling effects may have changed in a warmer climate.

Our study area is the contiguous United States. We provide a regional-scale diagnosis based on a standard differentiation of the United States according to major catchments (Seaber et al. 1987). While no explicit delineations based on water- or energy-limited considerations are made among these catchments, it is broadly known that the overall basins of the Southwest are moisture limited (i.e., low runoff efficiency and high evapotranspiration ratio) compared to those in the Northeast and Northwest that are energy limited (i.e., high runoff efficiency and low evapotranspiration ratio). The two distinct regimes determine how strongly soil moisture constrains land evaporation and resulting feedbacks to the atmosphere (i.e., weak or strong landatmosphere coupling), thereby having important implications for the occurrence of drought and heat waves (Seneviratne et al. 2010).

We analyze drought-heat wave as a compound event of heat-wave temperatures, precipitation deficits, and soil moisture deficits (within a shallow 10-cm surface layer) during the summer season (June-August). The use of multiple indicators has been suggested by many studies in order to characterize both dynamic and thermodynamic processes involved in drought conditions (Palmer 1965; Cancelliere and Salas 2004; Song and Singh 2010; Madadgar and Moradkhani 2013; Chen et al. 2013; Mirabbasi et al. 2012). Two 1200-yr equilibrium simulations of a coupled climate model, that is, the Community Earth System Model, version 1 (CESM1.0;
Kay et al. 2015), subjected to respective year-1850 (Y1850) and year-2000 (Y2000) radiative forcings are conducted. We first assess sensitivity of heat waves to soil moisture droughts for each hydrologic region under the nineteenth-century climate forcings, and then compare with that under current climate forcings. Differences between these two experiments reveal sensitivity of soil moisture-temperature feedbacks due to changes in external radiative forcing. We focus on the soil moisture-temperature relationship given its high relevance for drought-heat wave occurrences, although the soil moisture-precipitation relation is also examined.

To characterize the dependence between hot and dry conditions, arising through land-atmosphere interaction, our approach involves the application of vine copula. As described in section 2 (and the online supplemental material), vine copula, also known as pair-copula construction, provides a solution for formulating multidimensional distributions without requiring a conditional independence assumption (Aas et al. 2009). This approach in particular accounts for nonlinear behavior that may emerge with anomalous dry and hot extremes, a symptom of excessive sensible heating and reduced latent heating during severe soil moisture deficits (Lyon and Dole 1995). Section 3 presents results on hot droughts with a focus on the soil moisture-temperature relationship. Using the CESM1 long simulations for two equilibrium climate states, we diagnose hot drought statistics in both preindustrial and postindustrial/current climates. In addition, by computing anomalies for current conditions with respect to both Y2000 and Y1850 climatologies, we evaluate the relative contributions of changes in soil moisture-atmosphere coupling and long-term warming on the amplification of current U.S. heat waves. A discussion and conclusions in section 4 compare our modelbased results with observational evidence for changes in compound heat-wave-drought events and also address limitations associated with our use of a single modeling platform.

\section{Materials and methods}

\section{a. U.S. hydrologic units}

Adapted from Seaber et al. (1987), the U.S. Geological Survey divides the United States into hydrologic unit systems. We use the first level of classification that divides the United States into 21 large-scale major geographic areas and contains either the drainage area of a major river, such as the Missouri region, or the combined drainage areas of a series of rivers, such as the Texas-Gulf of Mexico region. Eighteen of the regions occupying the land area of the conterminous United 


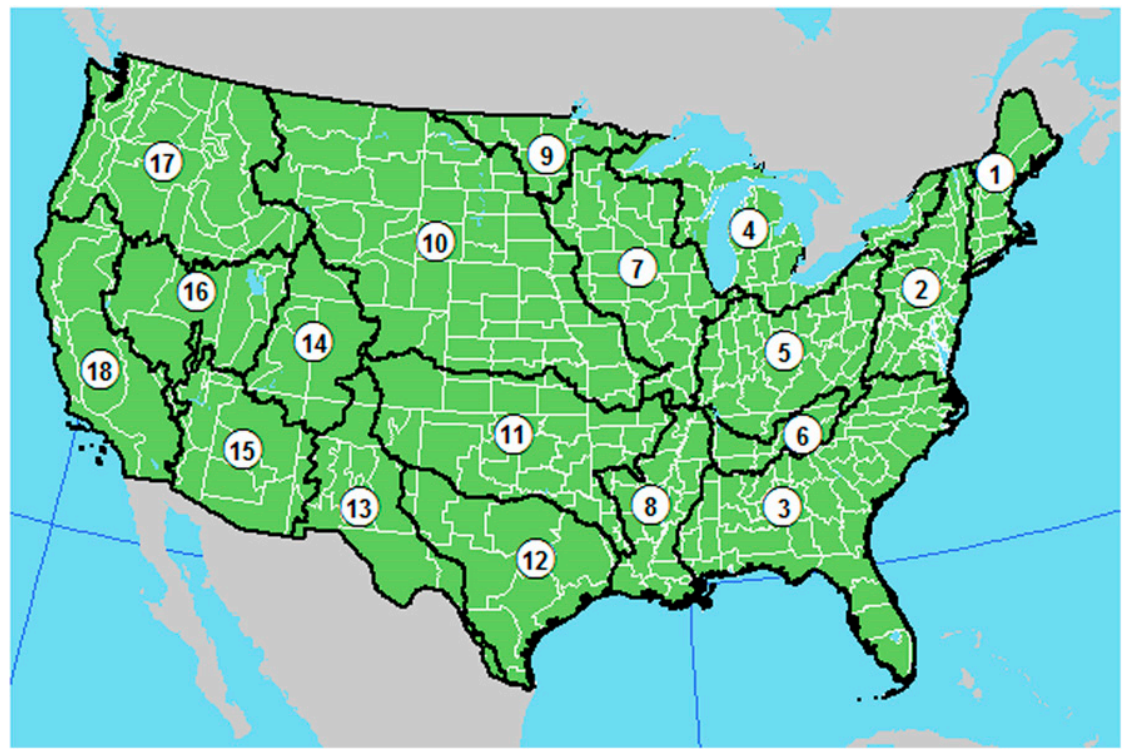

FIG. 1. Hydrologic units for the contiguous United States. Region 01: New England; Region 02: Mid-Atlantic; Region 03: South Atlantic-Gulf; Region 04: Great Lakes; Region 05: Ohio; Region 06: Tennessee; Region 07: Upper Mississippi; Region 08: Lower Mississippi; Region 09: Souris-Red-Rainy; Region 10: Missouri; Region 11: Arkansas-White-Red; Region 12: TexasGulf; Region 13: Rio Grande; Region 14: Upper Colorado; Region 15: Lower Colorado; Region 16: Great Basin; Region 17: Pacific Northwest; Region 18: California.

States are the focus herein (Fig. 1). Droughts can often be a dimension greater than the watershed scale of these individual basins, and the results will subsequently reveal that changes in heat-wave intensity during droughts span across multiple catchments. In other words, the results will speak to changes in behavior of heat waves closely related with meteorological/ agricultural droughts, while not necessarily being restricted by hydrologic droughts per se.

\section{b. CESM1 simulations and hot drought definition}

The data used in this study are from the National Center for Atmospheric Research CESM, a coupled model for simulating Earth's climate system (Kay et al. 2015). Its land representation includes sophisticated treatments of interaction between the land surface, soils, canopy and vegetation, and the overlying atmosphere. The land model (CLM4) explicitly represents biogeophysical processes including surface radiation interactions with vegetation, stomatal physiology, and photosynthesis (Riley et al. 2011). It includes 10 hydrologically active soil layers having a uniform depth of $3.8 \mathrm{~m}$ for active hydrology (Brunke et al. 2016). Many other studies have applied and systematically examined simulations of CESM1 (Neale et al. 2008; Hurrell et al. 2013; Wang et al. 2013; Marsh et al. 2013; Teng and Branstator 2017). For instance, Teng and Branstator
(2017) investigated the origin of the wave patterns associated with extreme ridges near the west coast of North America using a fully coupled Earth system model CESM1. Wang et al. (2013) used the CESM1 to understand the role of increased anthropogenic greenhouse gases in intensifying the dipole through warming in the western Pacific and associated enhancement in the teleconnection toward North America. We diagnose two 1200-yr monthly simulations of CESM1, driven by external radiative forcings of Y1850 and Y2000, respectively. The specified external forcings consist of greenhouse gases [e.g., $\mathrm{CO}_{2}, \mathrm{CH}_{4}, \mathrm{NO}_{2}, \mathrm{O}_{3}$, and chlorofluorocarbons (CFCs)] and natural and human-induced aerosols. The model simulations have been adapted to the 18 U.S. hydrologic units by computing an areal average for each of the basins. Grid points are first assigned to each of the basins individually, and areal averages are then constructed utilizing an area weighted average of all grid points within a particular basin.

Monthly temperature, precipitation, and $10-\mathrm{cm}$ soil moisture are derived from both experiments for each basin. We focus on total precipitation, total surface soil moisture, and averaged temperature for the months of June, July, and August and compute anomalies of the three quantities relative to each model experiment's summertime climatology. Hot drought is defined as a simultaneous occurrence of negative precipitation 


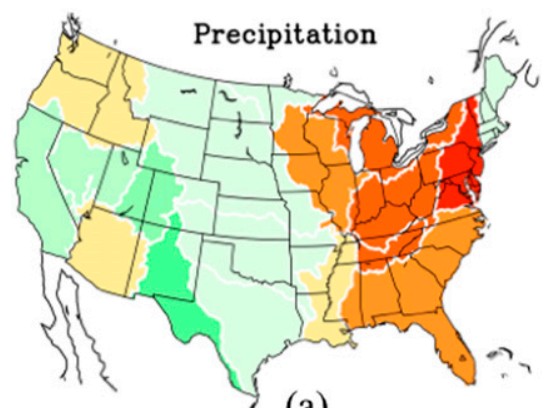

(a)

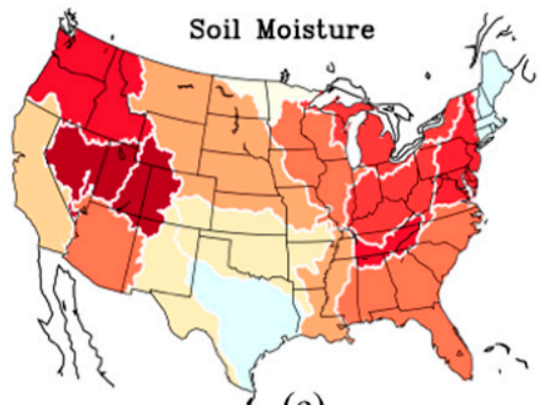

(c)

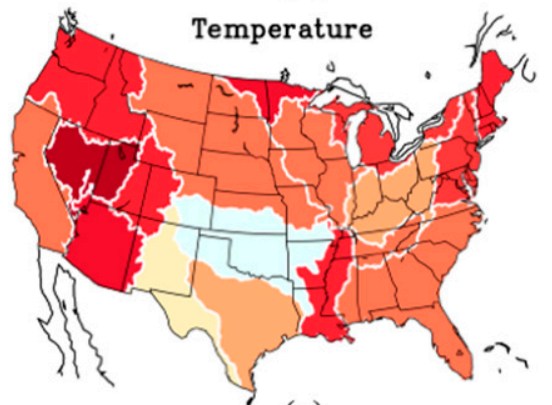

(e)
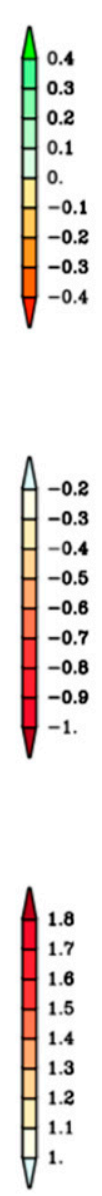

FIG. 2. (left) The difference between the Y2000 and Y1850 experiments for (a),(b) precipitation, (c),(d) soil moisture, and (e),(f) temperature during hot summer drought conditions. Only for precipitation and soil moisture, differences have been standardized relative to 1 standard deviation of their respective Y1850 simulations. (right) The 1 standard deviation of each variable in Y1850.

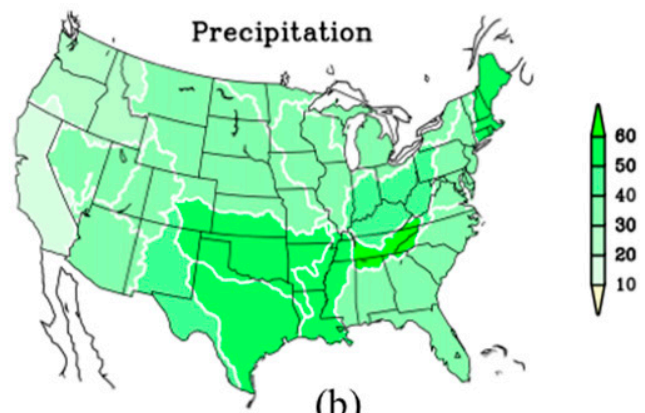

(b)

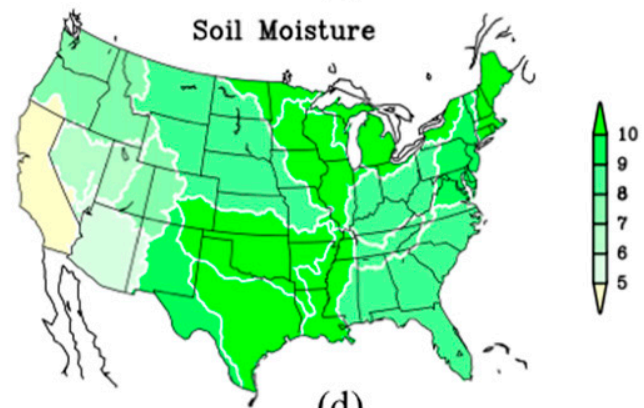

(d)

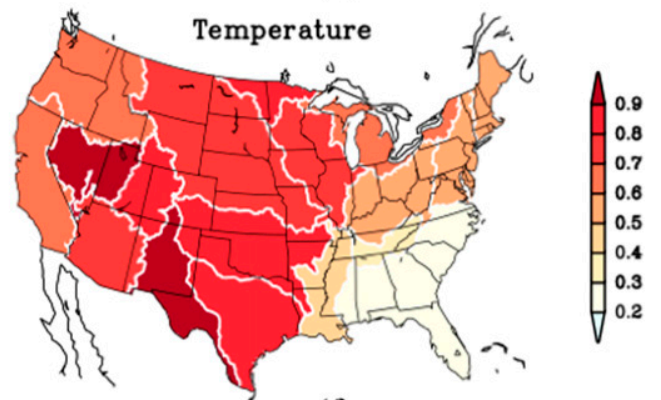

(f) anomalies, negative soil moisture anomalies, and positive temperature anomalies relative to the summertime seasonal averages. In addition, we identify and compare hot drought statistics relative to the climatology of Y1850 for both experiments, thereby also quantifying the anthropogenic warming effects on hot drought statistics. The drought/heat wave definition used in this study refers to seasonal events and thus should be distinguished from flash droughts that often occur over shorter periods. It is plausible that the summer drought studies herein constitute a multiseason prolonged event, which requires further research. The main point of this study is to examine changes of the drought-heat-wave relationship rather than to determine the meteorological drivers that may cause rapid onset or transition of soil moisture that typifies flash-drought events.

Figure 2 shows the long-term change for precipitation (Figs. 2a,b), soil moisture (Figs. 2c,d), and temperature (Figs. 2e,f) during summertime hot droughts at each region by comparing the two CESM1 experiments (see panels on the left). Except for temperature, changes of precipitation and soil moisture have been standardized relative to their respective one standard deviation of the preindustrial simulation. This baseline is given on the right showing the standard deviation of each variable in Y1850. As shown, response of precipitation and surface soil moisture to the long-term climate change is largely consistent; that is, higher precipitation leads to higher soil moisture content and vice versa. An exception is the central and southwestern United States, whereof the surface soil layer experiences more deficits than that implied by changes of precipitation alone in the early 
twenty-first century. Unlike precipitation and soil moisture, temperature (Fig. 2e) increases more uniformly over the contiguous United States. A spatial average of $1.5^{\circ} \mathrm{C}$ increase occurs in the current climate relative to the preindustrial climate. Considering both surface soil moisture (Fig. 2c) and temperature (Fig. 2e), this long-term change consists of drier and warmer conditions for most regions of the United States. The marked analogy of their spatial distributions suggests a tight relationship between soil moisture and temperature during drought conditions.

\section{c. Vine copula}

We probe into the relationship between drought and heat waves with vine copula, a flexible statistical tool in high-dimensional dependence modeling. It builds upon bivariate copula, a joint distribution on the unit interval with uniform margins of two variables (Sklar 1959; Madadgar and Moradkhani 2013; Mirabbasi et al. 2012; AghaKouchak et al. 2014). In our analysis, univariate distributions including normal, gamma, lognormal, and Weibull distributions are examined. According to the least root-mean-square errors and chi-square goodnessof-fit tests (not shown), we identify the best-fit marginal distributions for each variable of interest and apply them consistently between Y1850 and Y2000 simulations, thereby allowing a fair comparison.

Leveraging from bivariate copulas (Kurowicka and Cooke 2007; Aas and Berg 2009; Kurowicka 2011; Brechmann and Schepsmeier 2013; Ren et al. 2014; Sarhadi et al. 2018), a graphical method for constructing multivariate distributions is developed through a process of pair-copula constructions (Joe 1996, 1997; Bedford and Cooke 2002). Canonical vines ("C-vines") and drawable vines ("D-vines") are two boundary cases of pair-copula constructions. Here we employ a threedimensional C-vine and highlight its feature for evaluating the importance of conditional relationships between variables and processes that capture underlying physical factors involved in their interdependence during drought/heat waves. Refer to Fig. 3 for a graphical representation of a three-dimensional C-vine. We assign specific orders to each variable, the role of which is to establish a conditioning sequence in the pair-copula constructions: first variable 1 is conditioned on, then variable 2, and so on (Czado et al. 2012; Brechmann and Schepsmeier 2013). On each edge label, we implement suitable copulas such that a joint distribution can be built with bivariate copulas and conditional copulas. By ordering these variables appropriately, such as $\left(x_{1}, x_{2}, x_{3}\right)$ denoting variables ( $x_{\text {soil_moisture_deficit }}, x_{\text {heatwave_temperature, }}$ $x_{\text {precipitation_deficit }}$, we can write the three-dimensional density function as

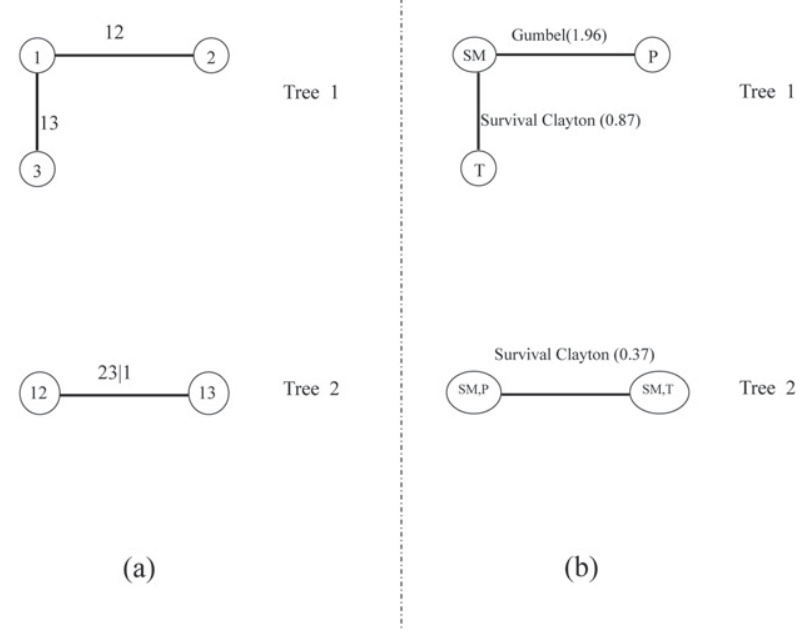

FIG. 3. Tree representation of the three-dimensional C-vine copula (a) with assigned labels and (b) with the corresponding climate variables at the root nodes. Labels $\mathrm{P}, \mathrm{SM}$, and T are short for precipitation deficits, surface soil moisture deficits, and hot summer temperature, respectively. The fitted bivariate copula and its dependence parameter are provided for each pair of variables for hydrologic unit 10 as an example.

$$
f_{123}=f_{1} f_{2} f_{3} c_{12} c_{13} c_{23 \mid 1}
$$

where $x_{1}$ is the conditioning factor in our three-dimensional vine copula. Five widely applied candidates-that is, Gaussian, $t$, Gumbel, Frank, and Clayton bivariate copulas-have been examined for building pair copulas of the pair-copula constructions. Following Schepsmeier et al. (2012), the most suitable one for each pair of variables renders the minimum Akaike information criterion.

Schirmacher and Schirmacher (2008, 14-16) and Aas et al. (2009) introduce the notion of the $h$ function as the conditional distribution function and derive its analytical formulation for pair-copula constructions. The sampling algorithm with canonical vine is simply an application of successive inverse forms of $h$ functions. In our case, surface soil moisture deficit is considered as the factor that conditions the joint distribution of precipitation deficits and heatwave temperature. If we assume that soil moisture deficits $x_{1}$ and high temperature $x_{2}$ have uniform margins of $u_{1}$ and $u_{2}$, respectively, simulations of $u_{2}$ under the condition of $u_{1}$ can be achieved via $h\left(u_{2} \mid u_{1}, \theta\right)$. More specifically, the first step is to set random probability levels of the conditional cumulative distribution, for example, $\tau=0.01,0.1, \ldots, 0.99$. Next, we make inference of $u_{2}$ from $C_{u_{2} \mid u_{1}}$ for each fixed probability $\tau$ using

$$
u_{1}=C_{u_{2} \mid u_{1}}^{-1}\left(\tau \mid u_{1}, \theta\right)=h^{-1}\left(\tau \mid u_{1}, \theta\right),
$$

where $C_{u_{2} \mid u_{1}}^{-1}$ is the inverse of the copula function known as the $\tau$ quantile curve of the copula (Min and Czado 

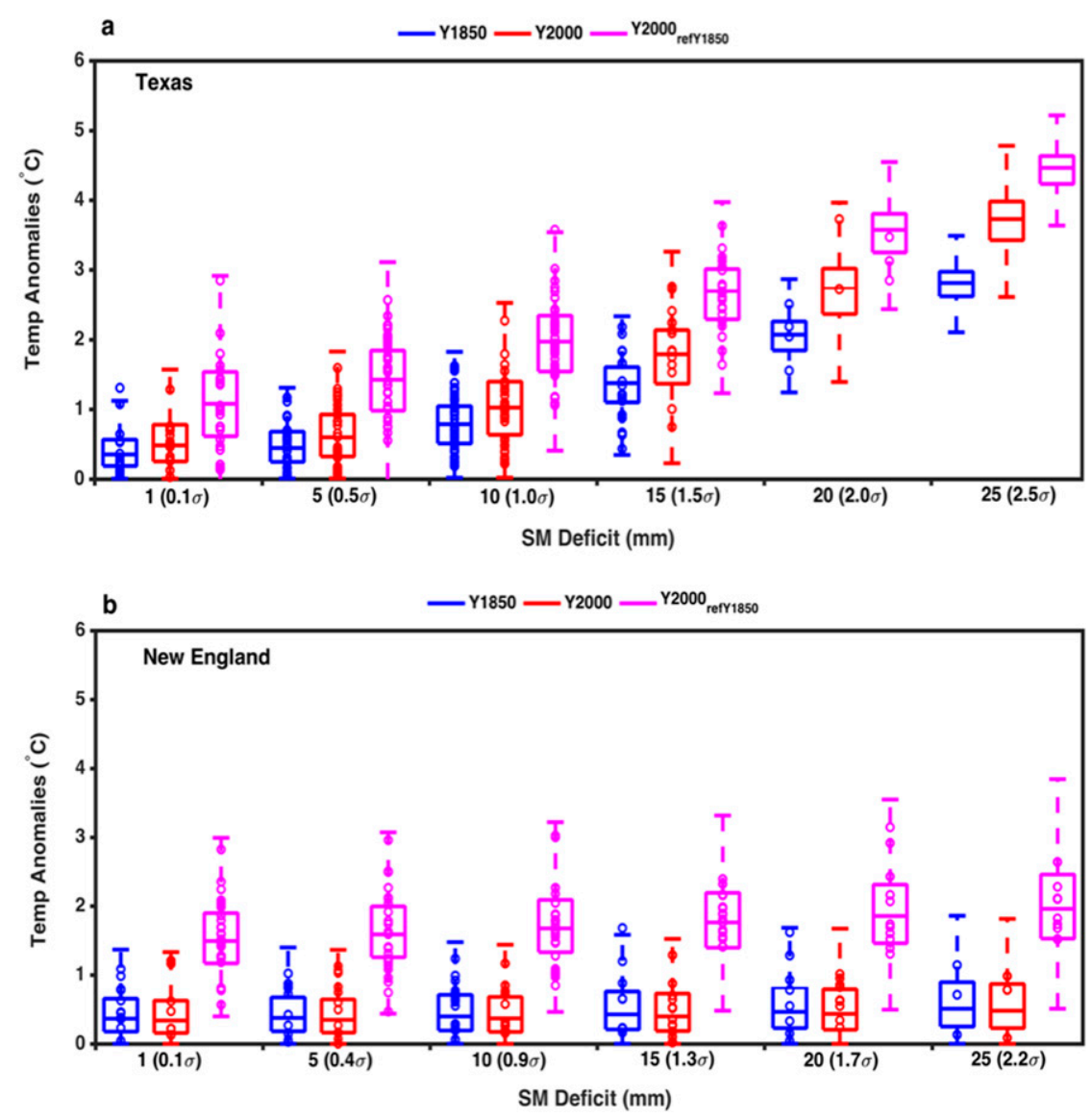

FIG. 4. Simulations of temperature anomalies corresponding to different severities of soil moisture deficits for Y1850 (blue) and Y2000 (red) experiments at the (a) Texas-Gulf and (b) New England basins. Magenta box-and-whisker results are delivered using anomalies of hot drought indicators of Y2000 relative to the climatology of Y1850. Boxplots are based upon 1000 generations from the conditional framework of vine copula, and dots are raw data from climate model simulations during the soil moisture deficits analogous to the assigned amounts. Boxplots show the median (center mark) and the 25th (lower edge) and 75th (upper edge) percentiles, and the whiskers quantify the $95 \%$ confidence interval.

2010). In this way, simulations of summertime heatwave temperatures can be produced with the $\tau$ th copulabased conditional quantile function, that is, $h^{-1}\left(\tau \mid u_{1}, \theta\right)$ as follows:

$$
x_{2}=F^{-1}\left[h^{-1}\left(\tau \mid u_{1}, \theta_{12}\right)\right]
$$

where $\theta_{12}$ controls the coupling strength between variables of $\left(x_{1}, x_{2}\right)$. In practice, we perform a Monte Carlo approach to generate 1000 uniformly distributed random values, that is, the $\tau$ values over the unit hypercube, and then calculate these 1000 realizations (simulations) of heat-wave temperature under the condition of soil moisture deficits following Eq. (2). For samples of precipitation deficits during various amounts of soil moisture deficits, the process is similar (not shown). For more details, refer to Liu et al. (2018). A summary for conditional distribution functions of the five bivariate copulas and their inverse forms can be found in the online supplemental material.

\section{Results}

\section{a. Soil moisture-temperature relation of the southern Great Plains}

Figure 4 presents the functional dependence of summertime temperature anomalies on drought severity as measured by soil moisture deficits. Anomalies are calculated relative to the respective long-term mean of Y1850 (blue) and Y2000 (red) climate states. We produce 1000 statistical model simulations of heat-waverelated temperatures as a function of drought severity 
using the vine-copula approach and summarize those statistics with box-and-whisker plots, and the raw CESM1 temperature associated with various soil moisture deficits is plotted with open circles. Results for the Texas-Gulf basin, a southern part of the southern Great Plains (top panel), show increasing heat-wave intensity as a function of soil moisture deficit. The statistical model simulation of such behavior compares well with the raw model data across weak and moderate drought severities regarding a $95 \%$ confidence interval. This suggests the relation between heat-wave temperatures and land surface conditions has been reasonably described by our multivariate framework and allows us to probe their interaction for extreme drought intensities for which few empirical measurements exist (i.e., toward the right-hand side of the box-and-whisker plots).

Under increasing drought intensity, the relation between land surface dryness and summertime temperature approximates an exponential curve over this southern Great Plains region, and also over the southwestern United States as a whole (not shown). For instance, there is an at least two- to threefold increase in heat-wave intensity as drought severity increases from 1 to $2 \sigma$ soil moisture deficits considering an interquartile range of the box-and-whisker plots. This is true for the behavior of hot droughts in the model simulations of both Y1850 and Y2000 climate states, thereby revealing a fundamental feature of land-atmosphere interactions associated with severe drought in general. The underlying physics is tied to the local surface energy balance-the magnitude of sensible to latent surface flux, as measured by the Bowen ratio, exhibits a strong nonlinear relationship with soil moisture over the Great Plains (e.g., Livneh and Hoerling 2016). As soil moisture vanishes for more severe drought, cooling by evapotranspiration likewise vanishes resulting in amplification of surface warming because of the dominance of sensible heating (e.g., Eltahir 1998). Such a relationship will also depend on the background climatological moisture state, and subsequent results for moisture-abundant regions will demonstrate a different relationship between heat waves and drought severity.

Although this nonlinear relationship exists in both nineteenth century and the current climates, our results reveal a more rapid increase in heat-wave intensity with soil moisture deficits under current climate forcings. In other words, the results are suggestive of a strengthened soil moisture-atmosphere coupling leading to amplified heat waves during drought under current climate forcing, particularly during more severe soil moisture deficits. For instance, the magnitude of heat waves associated with a $20-\mathrm{mm}$ soil moisture deficit under Y2000 conditions is comparable to that associated with 25-mm soil moisture deficits under Y1850 conditions. It should be noted that these stronger heat waves are not due to the additive effect of warming associated with climate change, as shown in Fig. 2. Rather, since all anomalies in the construction of Fig. 4 are relative to each models' climatology, the more intense heat waves for severe droughts are suggestive that an additional and important effect of anthropogenic warming is enhancing soil moisture-temperature coupling.

To illustrate the combined effects of the aforementioned long-term warming and enhanced soil moisture feedbacks, Fig. 4 also presents box-and-whisker plots wherein the anomalies of Y2000 are calculated with respect to the climatological mean of Y1850 (magenta). The entire distribution of temperature anomalies shifts to warmer departures as a result of the anthropogenically forced warming trend in CESM1. Consistent with an overall $+1^{\circ} \mathrm{C}$ warming over the southern Great Plains (see Fig. 2), the magnitude of heat waves for all droughtseverity categories is likewise approximately $1^{\circ} \mathrm{C}$ greater than when anomalies are computed relative to Y2000 references. Of particular interest, however, is that under extreme drought conditions, stronger heat waves of Y2000 relative to Y1850 arise in almost equal proportions because of enhanced coupling effects and from the long-term warming trend effect. As shown by the box-and-whisker results, heat-wave variability of Y2000 gradually increases and overlaps more than half of the mean anthropogenic warming signal during stronger droughts. Analogous results, to be summarized shortly, are found over a wide region of the southern and western United States, regions known for their water-limited characteristics. Overall, these results indicate that strengthened land-atmosphere feedback is a significant physical driver for increasing occurrences of droughtrelated extreme heat waves, particularly over the semiarid and arid regions of the United States.

\section{b. Soil moisture-temperature relation of the northeastern United States}

To contrast with results for the southern Great Plains, the bottom panel of Fig. 4 presents analysis for the New England region whose climate is energy limited. We note once again the good agreement between the statistics of drought-heat waves based on the vine-copula model and the raw data from the climate model simulations. However, the behavior of these events, and their sensitivity to climate change, are markedly different from that occurring over the more water-limited southern Great Plains. First, there is little sensitivity of summertime surface temperatures to increasing drought severity. Indeed, the magnitude of temperature anomalies is virtually the same for soil moisture deficits of 
about 2 standardized departures as for about 0.5 standardized departures. This insensitivity may merely reaffirm the overall abundance of soil moisture in this wet region such that a strong nonlinearity inherent in the Bowen ratio is not readily engaged even under severe drought conditions. In wet regions, soil moisture does not have a strong control on evapotranspiration variability, thereby limiting its impacts on the near-surface climate (Lorenz et al. 2010). It may also indicate that large-scale atmospheric circulation associated with droughts in the Northeast United States are different and more relevant for driving the surface energy budget than for southern and southwestern U.S droughts (e.g., Namias 1966,1983). There will be further suggestions to this effect when we summarize our results for the entire United States in the next section.

Second, there is little distinction between droughtheat-wave events, and especially the maximum intensity of heat waves achieved, in Y1850 versus Y2000 model statistics. Implied hereby is no appreciable change in soil moisture feedbacks, even though surface air temperatures rise by nearly $2^{\circ} \mathrm{C}$ over the Northeast, nearly double the surface warming over the southern Great Plains (see Fig. 4a). On first consideration, it appears plausible that a strengthened soil moisture feedback might arise over the southern Great Plains relative to New England because the mean soil moisture declines appreciably more in the former region compared to the latter (see Fig. 4b). However, subsequent analysis will show that the spatial map of mean soil moisture change for the United States as a whole is poorly related to the map of change in heat-wave intensity during droughts. Rather, we suspect that the change in mean land surface climate in the moist Northeast is simply insufficient to engage a heightened heat-wave sensitivity even during extreme droughts. This is inherent in the physics undergirding the Bowen ratio. For example, diagnosis of the Bowen ratio's magnitude as a function of progressive soil drying by Livneh and Hoerling (2016, their Fig. 10) reveals insensitivity of temperatures to soil moisture for a wide range of soil moisture decreases, followed by a rapid exponential rise in that ratio at sufficiently low soil moisture. Though their analysis was for the central Great Plains, it is plausible that a similar physics may account for the insensitivity of soil moisture feedbacks in the wetter Northeast compared to the more arid southern and southwestern United States in our CESM1 experiments. This finding is supported by Zhang et al. (2008) who showed that strong coupling between soil moisture and summer mean temperature is not visible over many wet areas, for example, the northeastern United States. They explained that the existence of high soil moisture variability is a necessary, but not sufficient,
TABLE 1. A summary of hydrologic basins where statistically significant (at $5 \%$ significance level) changes of heat-wave intensity occur during severe droughts, i.e., $2 \sigma$ of preindustrial soil moisture deficits. Percent changes are calculated between Y2000 and Y1850. Positive values indicate higher mean heat-wave temperatures in the current climate relative to the historical period, and otherwise is negative.

\begin{tabular}{lcc}
\hline \hline \multicolumn{1}{c}{ Hydrologic units } & $\begin{array}{c}\text { Hydrologic } \\
\text { code }\end{array}$ & $\begin{array}{c}\text { Percent change } \\
\text { for severe drought }\end{array}$ \\
\hline Lower Mississippi & 8 & 43 \\
Lower Colorado & 15 & 32 \\
Texas-Gulf & 12 & 31 \\
California & 18 & 29 \\
Souris-Red-Rainy & 9 & 13 \\
Great Basin & 16 & 13 \\
Rio Grande & 13 & 11 \\
Upper Colorado & 14 & 8 \\
Arkansas-White-Red & 11 & 5 \\
Ohio & 5 & -9 \\
Great Lakes & 4 & -10 \\
Mid-Atlantic & 2 & -21 \\
\hline
\end{tabular}

condition for strong land-atmosphere feedback on temperature to exist, as a region with small variability would not be expected to have strong feedback.

Nonetheless, heat waves during droughts over the Northeast do become more intense, although solely because of the additive effect of the overall warming trend. The magenta box-and-whisker plots illustrate hot drought statistics of Y2000 referenced to the Y1850 climatology. These results show a roughly $2^{\circ} \mathrm{C}$ increase in summer temperature anomalies during droughts of comparable intensity in Y2000 versus Y1850 climate. These stronger heat waves are consistent with the roughly $2^{\circ} \mathrm{C}$ warming trend. We reiterate our finding that the soil moisture feedbacks appear not to have a significant bearing on the occurrence of these hotter droughts, because soil moisture-temperature coupling is both weak over this region and insensitive to the magnitude of the region's climate change since the late nineteenth century.

\section{c. Regional dependency of U.S. heat waves on droughts in the context of climate change}

Table 1 summarizes regions of statistically significant (at a 5\% significance level) change in heat-wave intensity during severe droughts based on the 18-catchment analysis. Shown is the change in heat-wave intensity during droughts that is beyond that arising from the warming trend alone. Our interpretation is that, especially over the southern and southwestern United States, this additional effect is symptomatic of increasing soil moisture feedback. We compare the median values of red and blue boxand-whiskers (see Fig. 4) associated with $2 \sigma$ of soil 
a

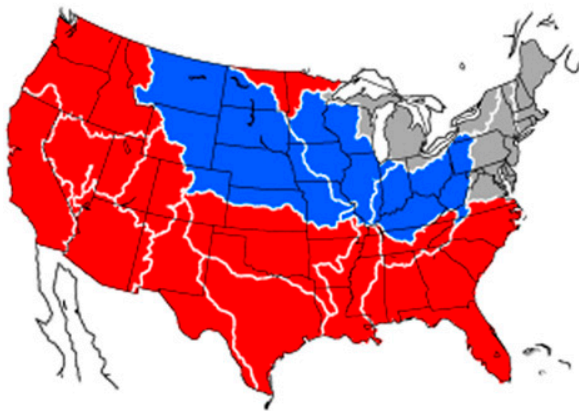

b

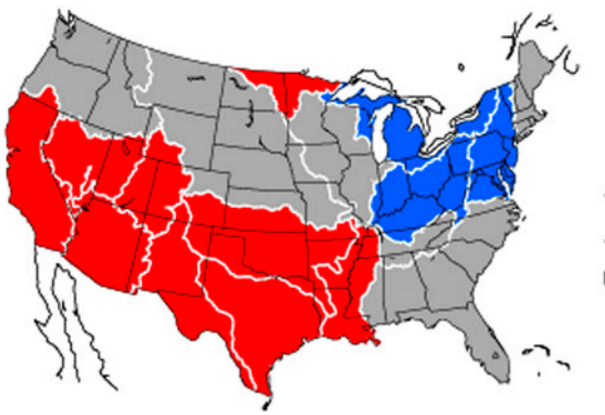

SM Deficit $(2 \sigma)$

FIG. 5. The $t$-test result for changes in heat-wave intensity corresponding to (a) 1 and (b) 2 standard deviations of soil moisture deficits in the preindustrial climate state. If the increases (or decreases) in the mean or variability of heat-wave temperatures since the nineteenth century are statistically significant at $5 \%$ significance level in a hydrologic unit, that unit is colored red (or blue), and places showing no significant changes are colored gray. Statistical significance is examined by a $t$ test with unequal variances (referred to as a Welch's $t$ test).

moisture deficits, and positive percentages indicate higher heat-wave temperatures in current versus nineteenth-century climates. The majority of regions experience more intense heat waves with particularly large increases over the southern and southwestern United States. Only a few regions, principally in the Ohio Valley and Great Lakes regions, experience decreased heat-wave intensity during droughts. This is so despite an overall mean temperature rise and soil moisture decline in those areas. Reasons for such declines are unclear from our analysis alone, but it is possible that dynamical changes in atmospheric circulation patterns associated with drought events may be occurring in CESM1, and that such dynamical processes may be especially relevant in driving changes in the surface energy balance over the northern United States during summer.

Figure 5 shows the regional distribution of the changes in heat-wave intensity over the contiguous United States. Results illustrate how heat waves change during both moderate-intensity droughts (left panel) and extreme-intensity drought (right panel), not including the additional effect of the long-term warming trend. Heat-wave intensity increases over much of the southern Great Plains and southwestern United States. The results of our focused diagnosis on the Texas-Gulf catchment (see section 3a) are thus seen to be representative of a broad region spanning the southern and southwestern United States. By contrast, the northern United States generally experiences no change in heatwave intensity, or even a reduction in some regions. The results are broadly similar for moderate versus extreme drought intensities - the U.S. pattern of change in heatwave intensity has a distinctive north-south dipole structure. In those areas where little relation is found between heat-wave strength and soil moisture deficits such as the North and Northeast regions, soil moisturetemperature coupling (which is weak in a climatological sense) is likewise fairly stationary during the summertime hot drought occurrences. Our interpretation is that amplified heat-wave intensities over a continuum of drought severity over the southern and southwestern regions reflects a strengthened soil moisture feedback in a warmer climate. In contrast, an insensitivity of heatwave magnitudes to climate change over the north is symptomatic of an overall absence of heat-wave-drought relationships in their mean climates owing to overall moisture abundance in these regions.

\section{Discussion and conclusions}

Our analysis of CESM1 climate simulation leads to the conclusion that summertime drought-heat-wave relationships have changed significantly over the southern and southwestern United States because of anthropogenic climate change since the late nineteenth century. Beyond the increase in heat-wave intensities occurring simply from an overall warming trend due to anthropogenic climate change, a further temperature increase of comparable magnitude arises during severe droughts owing to increased soil moisture feedbacks. We find the latter effect to be most prominent in moisture-limited areas of the southern and southwestern United States. By contrast, the drought-heat wave relationship over northern U.S regions undergoes little change in the warmed climate, such that the long-term warming trend plays the primary role in intensified heat waves during droughts in those regions.

Such an overall U.S. pattern of heat-wave changes during droughts is materially different from those of the mean changes in the state variables including temperature, 
precipitation, and soil moisture. We suggest several factors that may explain the contrast in patterns of these mean changes versus the changes in extreme hot droughts. One is the role played by the surface moisture and energy balance, which broadly speaking has a meridional structure across the United States-a more energy-limited (but moisture abundant) north contrasted with a more moisture-limited (but energy abundant) south. These are of course broad categorizations, and it should be recognized that within the complex terrain of the West, both moisture and energy-limited locations reside within a single catchment (such as the Upper Colorado River basin, or the California drainage basins). Notwithstanding these local complexities, the large-scale results here suggest that the background climatological state appears to mitigate or enhance the sensitivity of heat waves during droughts under climate change. This was found to be clearly evident within the particular equilibrium climates of CESM1 simulations (Y1850 and Y2000) - heat waves being mostly insensitive to drought severity in the north but highly sensitive in the south. The magnitude of that sensitivity over the south increased in a climate that warmed (and in which soils also dried), heightening the soil moisture feedback in those areas that already had a strong feedback operative in their mean states. By contrast, little climate change effect occurred in areas that did not have a strong feedback operative in their mean states. We speculate that a catalyst for heightened (positive) sensitivity arises when a region's climate is forced toward aridity via mean anthropogenic change such that occurrences of intermittent heightened dryness during drought events exposes stronger nonlinearity inherent in Bowen ratio physics. It is unclear if such an argument holds for understanding the regions that show decreases in heat-wave intensity during drought, such as portions of the Ohio Valley and Northeast. It is plausible in those areas especially that dynamical processes are important, especially since summertime droughts over the northern United States can be associated with appreciable shifts in the jet stream (see Namias 1983). Whether the underlying dynamical causes for droughts differ among the Y2000 versus Y1850 statistics of CESM1 is a subject of further research. We should also note that the analysis, by having focused solely on the summer season, has not addressed the role of the seasonality in soil moisture anomalies nor how climate change affects the seasonality in soil moisture. In other words, changes in antecedent land surface conditions may also occur, and these could affect inferences on the physical nature of the simultaneous relationships between summer temperature, soil moisture, and rainfall conducted herein.

It is important to emphasize that the results of this paper are based on a single climate model, and the structural uncertainty of the findings remains to be assessed, for example, by comparison with other models run in similar configurations. There is also the question of whether the sensitivity of compound drought-heat waves to climate change occurring in CESM1 can be identified, let alone verified, in historical observations. We note the observational study of Chiang et al. (2018), who explored a similar research question using observational data over the contiguous United States as we pursued via our model investigation. The authors examined temperature shifts associated with drought severities of mainly moderate (i.e., D0 and D1) intensity between two periods, that is, 1902-51 versus 1965-2014. Their analysis indicates compound occurrences of drought with heat waves are becoming more frequent in several portions of the United States, including the semiarid Southwest. An important finding of theirs is that heat waves during droughts have been more intense in recent decades, having magnitudes beyond expectations from simple linear additive effects of a warming trend. Their paper thus gives some empirical evidence supporting, at least qualitatively, our model-based findings. We note that neither the observational analysis nor the model-based analysis alone can be sufficient to confirm the detection and causality of change in compound drought-heat-wave events; yet, the broad agreement between these two independent studies makes a stronger case for change in drought-heat-wave relationships, particularly over the southern and southwestern United States, owing to the human-induced climate change.

A strength of our approach is that it facilitates new insights on how, and by how much, human-induced climate change affects compound "hot droughts" over the contiguous United States. Although based on a single model, the unique design of the experiments and the large sample size of the runs $(1200 \mathrm{yr})$ allows robust diagnosis of changes in land-atmospheric feedbacks during hot drought events of varying magnitudes for preindustrial versus current climate. In particular, the availability of such long simulations permits a statistically meaningful estimate of changes in tail events that would be of great societal relevance, and analysis that is otherwise very difficult from the short instrumental record. Despite these strengths, we note that the generality of our results needs to be assessed for their consistency across different climate models. Global land models have limitations including uncertainties, different parameterizations, and simplified vegetation dynamics in representing physical processes of moisture exchange (Marsh et al. 2013). These may result in biases in the sensitivities to meteorological forcing. And whereas the CESM1 land representation is among the more sophisticated systems 
that explicitly represents biogeophysical processes including surface radiation interactions with vegetation, stomatal physiology, and photosynthesis (Riley et al. 2011), the structural uncertainty of results presented herein using that particular model will need to be assessed by comparison with results derived from similar experiments using other state-of-the-art models.

In closing, our study takes a step toward increasing knowledge on the interactions between drought and heat waves in a warming world, presenting evidence that such events may become especially severe in waterlimited regions, in terms of both their frequency and intensity. We expect that these preliminary findings, along with further studies needed to confirm our results, will be important to facilitate better communication with risk managers who are seeking to better understand how climate change exposes vulnerabilities of human health, water supply, and agricultural productivity, all of which are susceptible to compound drought-heat waves.

Acknowledgments. The authors acknowledge support from NOAA's Climate Program Office MAPP program and the support for this work provided by the PSD base support. The authors also acknowledge the CESM Large Ensemble Community Project and supercomputing resources provided by NSF/CISL/Yellowstone. The first author acknowledges support from the University of Arkansas. The authors thank Dr. Xiaowei Quan for providing CESM1 simulations.

\section{REFERENCES}

Aas, K., and D. Berg, 2009: Models for construction of multivariate dependence-A comparison study. Eur. J. Finance, 15, 639659, https://doi.org/10.1080/13518470802588767.

_ C. Czado, A. Frigessi, and H. Bakken, 2009: Pair-copula constructions of multiple dependence. Insur. Math. Econ., 44, 182-198, https://doi.org/10.1016/j.insmatheco.2007.02.001.

AghaKouchak, A., L. Cheng, O. Mazdiyasni, and A. Farahmand, 2014: Global warming and changes in risk of concurrent climate extremes: Insights from the 2014 California drought. Geophys. Res. Lett., 41, 8847-8852, https://doi.org/10.1002/ 2014GL062308.

Bedford, T., and R. M. Cooke, 2002: Vines: A new graphical model for dependent random variables. Ann. Stat., 30, 1031-1068, https://doi.org/10.1214/aos/1031689016.

Beniston, M., 2004: The 2003 heat wave in Europe: A shape of things to come? An analysis based on Swiss climatological data and model simulations. Geophys. Res. Lett., 31, L02202, https://doi.org/10.1029/2003gl018857.

Brechmann, E. C., and U. Schepsmeier, 2013: Modeling dependence with $\mathrm{C}$-and D-vine copulas: The R-package CDVine. J. Stat. Software, 52, 1-27, https://doi.org/10.18637/jss.v052.i03.

Brunke, M. A., and Coauthors, 2016: Implementing and evaluating variable soil thickness in the Community Land Model, version 4.5 (CLM4. 5). J. Climate, 29, 3441-3461, https://doi.org/ 10.1175/JCLI-D-15-0307.1.
Cancelliere, A., and J. D. Salas, 2004: Drought length properties for periodic-stochastic hydrologic data. Water Resour. Res., 40, W02503, https://doi.org/10.1029/2002WR001750.

Chang, F. C., and J. M. Wallace, 1987: Meteorological conditions during heat waves and droughts in the United States Great Plains. Mon. Wea. Rev., 115, 1253-1269, https://doi.org/ 10.1175/1520-0493(1987)115<1253:MCDHWA > 2.0.CO;2.

Chen, L., V. P. Singh, S. Guo, A. K. Mishra, and J. Guo, 2013: Drought analysis using copulas. J. Hydrol. Eng., 18, 797-808, https://doi.org/10.1061/(ASCE)HE.1943-5584.0000697.

Chiang, F., O. Mazdiyasni, and A. AghaKouchak, 2018: Amplified warming of droughts in southern United States in observations and model simulations. Sci. Adv., 4, eaat2380, https://doi.org/ 10.1126/sciadv.aat2380.

Cook, B. I., J. E. Smerdon, R. Seager, and S. Coats, 2014: Global warming and 21st century drying. Climate Dyn., 43, 2607-2627, https://doi.org/10.1007/s00382-014-2075-y.

, T. R. Ault, and J. E. Smerdon, 2015: Unprecedented 21st century drought risk in the American Southwest and Central Plains. Sci. Adv., 1, e1400082, https://doi.org/10.1126/ sciadv. 1400082

Czado, C., U. Schepsmeier, and A. Min, 2012: Maximum likelihood estimation of mixed C-vines with application to exchange rates. Stat. Modell., 12, 229-255, https://doi.org/10.1177/ 1471082X1101200302.

Dai, A., 2013: Increasing drought under global warming in observations and models. Nat. Climate Change, 3, 52-58, https:// doi.org/10.1038/nclimate1633.

Dirmeyer, P. A., 2006: The hydrologic feedback pathway for landclimate coupling. J. Hydrometeor., 7, 857-867, https://doi.org/ 10.1175/JHM526.1.

Dole, R., and Coauthors, 2011: Was there a basis for anticipating the 2010 Russian heat wave? Geophys. Res. Lett., 38, L06702, https://doi.org/10.1029/2010GL046582.

Durre, I., J. M. Wallace, and D. P. Lettenmaier, 2000: Dependence of extreme daily maximum temperatures on antecedent soil moisture in the contiguous United States during summer. J. Climate, 13, 2641-2651, https://doi.org/10.1175/15200442(2000)013<2641:DOEDMT>2.0.CO;2.

Eltahir, E. A., 1998: A soil moisture-rainfall feedback mechanism: 1. Theory and observations. Water Resour. Res., 34, 765-776, https://doi.org/10.1029/97WR03499.

Ferranti, L., and P. Viterbo, 2006: The European summer of 2003: Sensitivity to soil water initial conditions. J. Climate, 19, 36593680, https://doi.org/10.1175/JCLI3810.1.

Fischer, E. M., S. I. Seneviratne, D. Lüthi, and C. Schär, 2007a: Contribution of land-atmosphere coupling to recent European summer heat waves. Geophys. Res. Lett., 34, L06707, https:// doi.org/10.1029/2006GL029068.

_ _ _ , P. L. Vidale, D. Lüthi, and C. Schär, 2007b: Soil moisture-atmosphere interactions during the 2003 European summer heat wave. J. Climate, 20, 5081-5099, https://doi.org/ 10.1175/JCLI4288.1.

Hirschi, M., and Coauthors, 2011: Observational evidence for soilmoisture impact on hot extremes in southeastern Europe. Nat. Geosci., 4, 17-21, https://doi.org/10.1038/ngeo1032.

Hoerling, M., and Coauthors, 2013: Anatomy of an extreme event. J. Climate, 26, 2811-2832, https://doi.org/10.1175/JCLI-D-1200270.1.

Hurrell, J. W., and Coauthors, 2013: The Community Earth System Model: A framework for collaborative research. Bull. Amer. Meteor. Soc., 94, 1339-1360, https://doi.org/10.1175/BAMS-D12-00121.1. 
Joe, H., 1996: Families of $m$-variate distributions with given margins and $m(m-1) / 2$ bivariate dependence parameters. Distributions with Fixed Marginals and Related Topics, Lecture Notes Monogr., Vol. 28, 120-141, Institute of Mathematical Statistics, https://doi.org/10.1214/lnms/1215452614.

_- 1997: Multivariate Models and Multivariate Dependence Concepts. CRC Press, 424 pp.

Kay, J. E., and Coauthors, 2015: The Community Earth System Model (CESM) large ensemble project: A community resource for studying climate change in the presence of internal climate variability. Bull. Amer. Meteor. Soc., 96, 1333-1349, https://doi.org/10.1175/BAMS-D-13-00255.1.

Knutson, T. R., J. Kam, F. Zeng, and A. T. Wittenberg, 2018: CMIP5 model-based assessment of anthropogenic influence on record global warmth during 2016. Bull. Amer. Meteor. Soc., 99, S11-S15, https://doi.org/10.1175/BAMS-D-17-0104.1.

Kurowicka, D., 2011: Dependence Modeling: Vine Copula Handbook. World Scientific, $360 \mathrm{pp}$.

—_, and R. M. Cooke, 2007: Sampling algorithms for generating joint uniform distributions using the vine-copula method. Comput. Stat. Data Anal., 51, 2889-2906, https://doi.org/ 10.1016/j.csda.2006.11.043.

Liu, Z., L. Cheng, Z. Hao, J. Li, A. Thorstensen, and H. Gao, 2018: A framework for exploring joint effects of conditional factors on compound floods. Water Resour. Res., 54, 2681-2696, https://doi.org/10.1002/2017WR021662.

Livneh, B., and M. P. Hoerling, 2016: The physics of drought in the U.S. central Great Plains. J. Climate, 29, 6783-6804, https:// doi.org/10.1175/JCLI-D-15-0697.1.

Lorenz, R., E. B. Jaeger, and S. I. Seneviratne, 2010: Persistence of heat waves and its link to soil moisture memory. Geophys. Res. Lett., 37, L09703, https://doi.org/10.1029/2010GL042764.

Lyon, B., and R. M. Dole, 1995: A diagnostic comparison of the 1980 and 1988 U.S. summer heat wave-droughts. J. Climate, 8, 1658-1675, https://doi.org/10.1175/1520-0442(1995)008<1658: ADCOTA $>2.0 . \mathrm{CO} ; 2$.

Madadgar, S., and H. Moradkhani, 2013: Drought analysis under climate change using copula. J. Hydrol. Eng., 18, 746-759, https://doi.org/10.1061/(ASCE)HE.1943-5584.0000532.

Marsh, D. R., M. J. Mills, D. E. Kinnison, J. F. Lamarque, N. Calvo, and L. M. Polvani, 2013: Climate change from 1850 to 2005 simulated in CESM1 (WACCM). J. Climate, 26, 7372-7391, https://doi.org/10.1175/JCLI-D-12-00558.1.

Meehl, G. A., and C. Tebaldi, 2004: More intense, more frequent, and longer lasting heat waves in the 21 st century. Science, $\mathbf{3 0 5}$, 994-997, https://doi.org/10.1126/science.1098704.

Min, A., and C. Czado, 2010: Bayesian inference for multivariate copulas using pair-copula constructions. J. Financ. Econ., 8, 511-546, https://doi.org/10.1093/jfinec/nbp031.

Mirabbasi, R., A. Fakheri-Fard, and Y. Dinpashoh, 2012: Bivariate drought frequency analysis using the copula method. Theor. Appl. Climatol., 108, 191-206, https://doi.org/10.1007/s00704-011-0524-7.

Miralles, D. G., A. J. Teuling, C. C. Van Heerwaarden, and J. V. G. de Arellano, 2014: Mega-heatwave temperatures due to combined soil desiccation and atmospheric heat accumulation. Nat. Geosci., 7, 345-349, https://doi.org/10.1038/ngeo2141.

Mo, K. C., and D. P. Lettenmaier, 2015: Heat wave flash droughts in decline. Geophys. Res. Lett., 42, 2823-2829, https://doi.org/ 10.1002/2015GL064018.

Namias, J., 1966: Nature and possible causes of the northeastern United States drought during 1962-65. Mon. Wea. Rev., 94, 543-557, https://doi.org/10.1175/1520-0493(1966)094<0543: NAPCOT $>2.3 . \mathrm{CO} ; 2$.
, 1983: Some causes of United States droughts. J. Climate Appl. Meteor., 22, 30-39, https://doi.org/10.1175/1520-0450(1983) $022<0030:$ SCOUSD $>2.0$. CO 2 .

NCDC, 2012: State of the climate, national overview. National Climate Report-July 2012, NOAA, http://www.ncdc.noaa.gov/ sotc/national/2012/7.

Neale, R. B., J. H. Richter, and M. Jochum, 2008: The impact of convection on ENSO: From a delayed oscillator to a series of events. J. Climate, 21, 5904-5924, https://doi.org/10.1175/ 2008JCLI2244.1.

Palmer, W. C., 1965: Meteorological drought. Weather Bureau Research Paper 45, U.S. Department of Commerce, 58 pp., http://www.ncdc.noaa.gov/temp-and-precip/drought/docs/ palmer.pdf.

Peterson, T. C., and Coauthors, 2013: Monitoring and understanding changes in heat waves, cold waves, floods, and droughts in the United States: State of knowledge. Bull. Amer. Meteor. Soc., 94, 821-834, https://doi.org/10.1175/ BAMS-D-12-00066.1.

Ren, X., S. Li, C. Lv, and Z. Zhang, 2014: Sequential dependence modeling using Bayesian theory and D-vine copula and its application on chemical process risk prediction. Ind. Eng. Chem. Res., 53, 14 788-14 801, https://doi.org/10.1021/ie501863u.

Riley, W. J., Z. M. Subin, D. M. Lawrence, S. C. Swenson, M. S. Torn, L. Meng, N. M. Mahowald, and P. Hess, 2011: Barriers to predicting changes in global terrestrial methane fluxes: Analyses using CLM4Me, a methane biogeochemistry model integrated in CESM. Biogeosciences, 8, 1925-1953, https:// doi.org/10.5194/bg-8-1925-2011.

Sarhadi, A., M. C. Ausín, M. P. Wiper, D. Touma, and N. S. Diffenbaugh, 2018: Multidimensional risk in a nonstationary climate: Joint probability of increasingly severe warm and dry conditions. Sci. Adv., 4, eaau3487, https://doi.org/10.1126/ sciadv.aau3487.

Schär, C., P. L. Vidale, D. Luthi, and C. Frei, 2004: The role of increasing temperature variability in European summer heat waves. Nature, 427, 332-336, https://doi.org/10.1038/nature02300.

Schepsmeier, U., and Coauthors, 2012: VineCopula: Statistical inference of vine copulas. R-Project CRAN Repository, https:// cran.r-project.org/web/packages/VineCopula/index.html.

Schirmacher, D., and E. Schirmacher, 2008: Multivariate dependence modeling using pair-copulas. Tech. Rep., 2008 Energy Risk Management Symposium, Chicago, IL, Society of Actuaries, 52 pp, https://www.soa.org/globalassets/assets/files/ resources/essays-monographs/2008-erm-symposium/mono-2008m-as08-1-schirmacher.pdf.

Seaber, P. R., F. P. Kapinos, and G. L. Knapp, 1987: Hydrologic unit maps. USGS Water-Supply Paper 2294, 66 pp., http:// pubs.usgs.gov/wsp/wsp2294/pdf/wsp_2294.pdf.

Seager, R., and M. Hoerling, 2014: Atmosphere and ocean origins of North American droughts. J. Climate, 27, 4581-4606, https://doi.org/10.1175/JCLI-D-13-00329.1.

Seneviratne, S. I., D. Lüthi, M. Litschi, and C. Schär, 2006: Landatmosphere coupling and climate change in Europe. Nature, 443, 205-209, https://doi.org/10.1038/nature05095.

_ , and Coauthors, 2010: Investigating soil moisture-climate interactions in a changing climate: A review. Earth-Sci. Rev., 99, 125-161, https://doi.org/10.1016/j.earscirev.2010.02.004.

Sklar, A., 1959: Fonctions de répartition á n dimensions et leurs marges. Publications of the Institute of Statistics of the University of Paris, Vol. 8, University of Paris, Paris, France, 229-231.

Song, S., and V.P. Singh, 2010: Meta-elliptical copulas for drought frequency analysis of periodic hydrologic data. Stochastic 
Environ. Res. Risk Assess., 24, 425-444, https://doi.org/ 10.1007/s00477-009-0331-1.

Stefanon, M., F. D’Andrea, and P. Drobinski, 2012: Heatwave classification over Europe and the Mediterranean region. Environ. Res. Lett., 7, 014023, https://doi.org/10.1088/17489326/7/1/014023.

Teng, H., and G. Branstator, 2017: Causes of extreme ridges that induce California droughts. J. Climate, 30, 1477-1492, https:// doi.org/10.1175/JCLI-D-16-0524.1.

- — - G. A. Meehl, and W. M. Washington, 2016: Projected intensification of subseasonal temperature variability and heat waves in the Great Plains. Geophys. Res. Lett., 43, 2165-2173, https://doi.org/10.1002/2015GL067574.

Vidale, P. L., D. Lüthi, R. Wegmann, and C. Schär, 2007: European summer climate variability in a heterogeneous multi-model ensemble. Climatic Change, 81, 209-232, https://doi.org/ 10.1007/s10584-006-9218-z.

Walsh, J., and Coauthors, 2014: Our changing climate. Climate Change Impacts in the United States: The Third National Climate Assessment, J. M. Melillo, T. C. Richmond, and G. W. Yohe, Eds., U.S. Global Change Research Program, 19-67, https://doi.org/10.7930/J0KW5CXT.

Wang, S. Y., M. L'Heureux, and J. H. Yoon, 2013: Are greenhouse gases changing ENSO precursors in the western North Pacific? J. Climate, 26, 6309-6322, https://doi.org/10.1175/JCLI-D-1200360.1 .

Zhang, J., W. C. Wang, and L. R. Leung, 2008: Contribution of land-atmosphere coupling to summer climate variability over the contiguous United States. J. Geophys. Res., 113, D22109, https://doi.org/10.1029/2008JD010136. 